\title{
HUBUNGAN FUNGSI MANAJEMEN KEPALA RUANGAN DENGAN KEPATUHAN PERAWAT PELAKSANA DALAM PENERAPAN PATIENT SAFETY DI RUMAH SAKIT UMUM IMELDA PEKERJA INDONESIA MEDAN
}

\author{
${ }^{1}$ Edisyah Putra Ritonga, ${ }^{2}$ Eka Kristian Gulo \\ ${ }^{1}$ Dosen Prodi S-1Keperawatan, STIKes Imelda, Jalan Bilal Nomor 52 Medan \\ ,2.Alumni STIKes Imelda Medan \\ E-mail : ${ }^{1}$ ediritonga87@gmail.com \\ 2 ekakristiangulo@gmail.com
}

\begin{abstract}
ABSTRAK
Keselamatan pasien merupakan prioritas utama untuk dilaksanakan dan hal tersebut terkait dengan isu mutu dan citra perumahsakitan (Depkes RI, 2006). Patient safety culture dapat dimulai dari pemimpin, Kepala ruang merupakan manajer keperawatan yang langsung berhubungan dengan kegiatan pelayanan kesehatan pada pasien. Tujuan penelitian ini adalah untuk mengetahui hubungan fungsi manajemen kepala ruangan terhadap perawat pelaksana dalam penerapan patient safety di Rumah Sakit Umum Imelda Pekerja Indonesia Medan. Jenis penelitian ini adalah penelitian kuantitatif dengan desain penelitian adalah deskriptif korelasi, Populasi dalam penelitian ini adalah seluruh perawat pelaksana yang berada di salah satu rumah sakit di Medan yang berjumlah 134 orang dengan jumlah sampel sebanyak 57 dengan random sampling sistematis. Berdasarkan hasil penelitian menunjukkan bahwa ada hubungan antara fungsi manajemen kepala ruangan dengan kepatuhan perawat pelaksana dalam penerapan patient safety dengan nilai $p 0.000<0.05$ yang berarti ada hubungan yang positif yaitu jika fungsi manajemen kepala ruangan semakin baik maka kepatuhan perawat pelaksana dalam penerapan patient safety semakin baik. Diharapkan bagi rumah sakit agar dapat membekali kepada perawat yang ada dirumah sakit dengan pengetahuan yang baru tentang patient safety dengan melakukan sosialisasi atau pelatihan terkait dengan patient safety agar dapat malukukan asuhan keperawatan dengan optimal kepada semua pasien.
\end{abstract}

Kata Kunci: Fungsi Manajemen, Keamanan Pasien.

\section{ABSTRACT}

Patient safety is a top priority to be implemented and this is related to the issue of quality and image of the hospital (MOH, 2006). Patient safety culture can be started from the leader, the head of the room is a nursing manager who is directly related to health service activities in patients. The purpose of this study was to determine the relationship between the management function of the head of the room to the nurse nurses in the application of patient safety at the hospital Umum Imelda Pekerja Indonesia Medan. This type of research is quantitative research with research design is descriptive correlation, the population in this study were all nurses who were in one hospital in Medan, amounting to 134 people with a total sample of 57 by systematic random sampling. Based on the results of the study show that there is a relationship between the management function of the head of the room with the compliance of implementing nurses in the application of patient safety with a p value of $0.000<0.05$ which means there is a positive relationship if the management function of the head room is getting better. It is expected that hospitals can equip nurses in hospitals with new knowledge about patient safety by conducting socialization or training related to patient safety in order to optimally provide nursing care to all patients.

Keywords: Management Functions, Patient Safety.

\section{PENDAHULUAN}

Keselamatan pasien merupakan prioritas utama untuk dilaksanakan dan hal tersebut terkait dengan isu mutu dan citra sakit (Depkes RI, 2006). Pelayanan kesehatan pada dasarnya adalah untuk menyelamatkan pasien, namun dengan semakin berkembangnya ilmu dan teknologi pelayanan kesehatan khususnya di rumah sakit menjadi semakin komplek dan berpotensi terjadinya Kejadian Tidak Diharapkan apabila tidak dilakukan dengan hati-hati (Depkes RI, 2008). 

2011) mengembangkan dan mempublikasikan Kurikulum Panduan Keselamatan Pasien (Patient Safety Curriculum Guide), yang menyoroti tentang kebutuhan diseluruh dunia dengan tujuan meningkatkan keselamatan pasien dan untuk mengajarkan keterampilan yang berorientasi pada keselamatan pasien (Tingle, 2011).

Laporan yang diterbitkan oleh Institut of Mediciene (IOM) Amerika Serikat tahun 2000 tentang "To Err is Human, Building to Safer Health System" terungkap bahwa rumah sakit di Utah dan Colorado ditemukan Kejadian Tidak Diharapkan (KTD) sebesar 2,9\% dan 6,6\% diantaranya meninggal, sedangkan di New York ditemukan $3,7 \%$ KTD dan 13,6\% diantaranya meninggal. Lebih lanjut, angka kematian akibat KTD pada pasien rawat inap di Amerika Serikat berjumlah 33,6 juta per tahun berkisar 44.000 jiwa sampai 98.000 jiwa. Depkes, (2006) menyebutkan bahwa pada tahun 2004 WHO mempublikasikan KTD rumah sakit di berbagai negara yaitu Amerika, Inggris, Denmark dan Australia terjadi dengan rentang 3,2 -16,6\%.

Berdasarkan studi pendahuluan yang dilakukan di salah salah satu rumah sakit Umum Imelda Pekerja Indonesia Medan di Medan, dengan melakukan observasi dan wawancara kepada kepala ruangan dan perawat pelaksana. Peneliti menemukan bahwa perawat pelaksana kurang patuh dalam melakukan penerapan patient safety dan kepala ruangan terlihat kurang menjalankan fungsi manajemen untuk mencapai tujuan dan terlaksananya patent safety dengan baik. Kepala ruangan terlihat tidak memberikan supervisi terhadap pelaksanaan patent safety.

\section{METODE}

Tujuan dari penelitian ini untuk mengetahui hubungan fungsi manajemen kepala ruangan terhadap perawat pelaksana dalam penerapan patient safety di Rumah Sakit Umum Imelda Pekerja Indonesia Medan. Penelitian ini merupakan penelitian kuantitatif dengan menggunakan rancangan penelitian deskriptif korelasi, (Polit \& Beck. 2012).

Populasi dalam penelitian ini adalah seluruh perawat pelaksana yang berada di
Rumah Sakit Umum Imelda Pekerja Indonesia Medan yang berjumlah 134 orang dengan jumlah sampel dalam penelitian ini adalah sebanyak 57 orang perawat pelaksana. Teknik pengambilan sampel dilakukan dengan random sampling sistematis.

Analisis bivariat digunakan uji Chi Square, uji ini digunakan untuk mengetahui hubungan fungsi manajemen kepala ruang yang terdiri dari perencanaan, pengorganisasian, pengaturan staf, pengarahan, dan pengendalian dengan kepatuhan dalam penerapan patient safety.

\section{HASIL}

Tabel 1. Karakteristik Demografi Perawat Pelaksana $(\mathrm{N}=57)$

\begin{tabular}{lll}
\hline Karakteristik & F & $\mathbf{( \% )}$ \\
\hline Umur & & \\
21-25 tahun & 40 & 70,2 \\
26-30 tahun & 14 & 24,6 \\
$>$ 30 tahun & 3 & 5,3 \\
\hline Jenis kelamin & & \\
Laki-laki & 25 & 43,9 \\
Perempuan & 32 & 50,1 \\
\hline Pendidikan & & \\
DIII & 57 & 100 \\
Keperawatan & & \\
\hline Masa kerja & & \\
1-2 tahun & 29 & 50,9 \\
3-5 tahun & 22 & 38,6 \\
> 5 tahun & 6 & 10,5 \\
\hline \multicolumn{2}{c}{ Berdasarkan } & tabel 1 \\
\end{tabular}
demografi perawat pelaksana di atas dapat dilihat bahwa hasil penelitian menunjukkan mayoritas responden berusia diantara 21-25 tahun yaitu sebanyak 40 orang $(70,2 \%)$ dan minoritas usia respnden $>30$ tahun yaitu sebanyak 3 orang $(5,3 \%)$. Berdasarkan jenis kelamin mayoritas responden berjenis kelamin perempuan yaitu sebanyak 32 orang $(56,1 \%)$, minoritas berjenis kelamin laki-laki yaitu sebenyak 25 orang $(43,9 \%)$. Berdasarkan tingkat pendidikan bahwa pendidikan responden seluruhnya adalah DIII keperawatan yaitu sebanyak 57 orang $(100 \%)$, dan berdasarkan masa kerja mayoritas masa kerja responden diantara 1-2 tahun yaitu sebanyak 29 orang (50\%) dan minoritas masa kerja responden yaitu $>5$ tahun sebanyak 6 orang $(10,5 \%)$.

Tabel 2. Distribusi Frekuensi Fungsi Manajemen Kepala Ruangan ( $\mathrm{N}=57)$

\begin{tabular}{l}
$\begin{array}{l}\text { Fungsi Manajemen } \\
\text { Kepala Ruangan }\end{array}$ \\
\hline
\end{tabular}




\begin{tabular}{lll}
\hline Baik & 26 & 45,61 \\
\hline Kurang & 31 & 54,39 \\
\hline Jumlah & 57 & 100 \\
\hline
\end{tabular}

Berdasarkan tabel di atas dapat dilihat bahwa hasil penelitian menunjukkan pelaksanaan fungsi manajemen kepala ruangan adalah mayoritas kurang yaitu sebanyak 31 orang $(54,39 \%)$ dan minoritas baik yaitu sebanyak 26 orang $(45,61 \%)$.

Tabel 3. Distribusi Frekuensi Pelaksanaan Penerapan Patient Safety (N=57)

\begin{tabular}{lll}
\hline Penerapan Patient Safety & F & \% \\
\hline Patuh & 26 & 45,61 \\
\hline Tidak Patuh & 31 & 54,39 \\
\hline Jumlah & 57 & 100 \\
\hline
\end{tabular}

Berdasarkan tabel diatas distribusi frekuensi di atas, menunjukkan hasil penerapan patient safety adalah tidak patuh yaitu sebanyak 31 orang $(54,39 \%)$ dan minoritas adalah baik yaitu sebanyak 26 orang $(45,61 \%)$.

Tabel 4. Hubungan Fungsi Manajemen Kepala Ruangan Dengan Kepatuhan Perawat Pelaksana

Dalam Penerapan Patient Safety di Rumah Sakit Umum Imelda Pekerja Indonesia Medan

$(\mathrm{N}=57)$.

\begin{tabular}{llllll}
\hline & \multicolumn{2}{l}{$\begin{array}{l}\text { Kepatuhan } \\
\text { Pelaksana }\end{array}$} & Perawat & \\
& $r$ & $p$ & & & \\
\hline $\begin{array}{l}\text { Fungsi } \\
\text { Manajemen } \\
\text { Kepala Ruangan }\end{array}$ & 0,439 & 0,000 & $\begin{array}{l}\text { Ada hubungan yang signifikan antara fungsi } \\
\text { manajemen kepala ruangan dengan kepatuhan } \\
\text { perawat pelaksana. }\end{array}$ \\
\hline
\end{tabular}

Berdasarkan tabel diatas didapatkan nilai $r$ sebesar 0.439 yang menunjukkan bahwa kekuatan hubungan antara fungsi manajemen kepala ruangan dengan kepatuhan perawat pelaksana dalam penerapan patient safety pada kategori "Sedang" dengan nilai $p 0.000<0.05$. Hal ini menjelaskan bahwa terjadi penolakkan terhadap Ho atau Ha diterima sehingga disimpulkan ada hubungan yang signifikan antara kedua variabel, arah hubungan adalah positif yaitu jika fungsi manajemen kepala ruangan semakin baik maka kepatuhan perawat pelaksana dalam penerapan patient safety semakin baik.

\section{PEMBAHASAN}

\section{Fungsi Manajemen Kepala Ruangan di Rumah Sakit Umum Imelda Pekerja Indonesia Medan}

Berdasarkan hasil penelitian penelitian yang telah dilakukan terhadap 57 orang sebagai responden di Rumah Sakit Umum Imelda Pekerja Indonesia Medan menunjukkan pelaksanaan fungsi manajemen kepala ruangan adalah mayoritas kurang yaitu sebanyak 31 orang $(54,39 \%)$ dan minoritas baik yaitu sebanyak 26 orang $(45,61 \%)$. Kepala ruang adalah seseorang yang diberikan tanggung jawab dan wewenang dalam mengatur dan mengendalikan kegiatan pelayanan keperawatan diruang rawat. Berhasil atau tidaknya pelaksanaan asuhan keperawatan sangat tergantung pada kepemimpinan seorang kepala ruangan, peran kepala ruangan diantaranya adalah seorang pemimpin di ruangan yang mengendalikan dan menilai pelaksanaan asuhan keperawatan yang telah ditentukan, kebenaran dan ketepatan program pengembangan pelayanan keperawatan, mengatur dan mengkoordinasi seluruh kegiatan pelayanan diruang rawat melalui kerjasama dengan petugas lain (Kartono, 2008).

Kepatuhan Perawat Pelaksana Dalam Penerapan Patient Safety di Rumah Sakit Umum Imelda Pekerja Indonesia Medan

Berdasarkan hasil penelitian penelitian yang telah dilakukan terhadap 57 orang sebagai responden di Rumah Sakit Umum Imelda Pekerja Indonesia Medan menunjukkan bahwa kepatuhan perawat pelaksana dalam penerapan patient safety adalah kurang patuh yaitu sebanyak 31 orang $(54,39 \%)$ dan minoritas adalah patuh yaitu sebanyak 26 orang $(45,61 \%)$. Menurut asusmsi peneliti penerapan patient safety masih dikategorikan kurang patuh dikarenakan kurangnya sosialisasi dari pihak rumah sakit tentang pentingnya keselamatan pasien dan juga kurangnya 
pengawasan/supervisi terhadap perawat pelaksana dalam penerapan patient safety.

\section{Hubungan Fungsi Manajemen Kepala Ruangan Dengan Kepatuhan Perawat Pelaksana Dalam Penerapan Patient Safety di Rumah Sakit Umum Imelda Pekerja Indonesia Medan}

Berdasarkan hasil penelitian didapatkan nilai $r$ sebesar 0.439 yang menunjukkan bahwa kekuatan hubungan antara fungsi manajemen kepala ruangan dengan kepatuhan perawat pelaksana dalam penerapan patient safety pada kategori "Sedang" dengan nilai $p 0.000<0.05$. Hal ini menjelaskan bahwa terjadi penolakkan terhadap Ho atau $\mathrm{Ha}$ diterima sehingga disimpulkan ada hubungan yang signifikan antara kedua variabel, arah hubungan adalah positif yaitu jika fungsi manajemen kepala ruangan semakin baik maka kepatuhan perawat pelaksana dalam penerapan patient safety semakin baik.

\section{KESIMPULAN}

1. Berdasarkan menunjukkan

$$
\text { hasil }
$$
pelaksanaan

penelitian mayoritas kurang yaitu sebanyak 31 orang $(54,39 \%)$ dan minoritas baik yaitu sebanyak 26 orang $(45,61 \%)$.

2. Berdasarkan hasil penelitian kepatuhan perawat pelaksana dalam penerapan patient safety adalah kurang patuh yaitu sebanyak 31 orang $(54,39 \%)$ dan minoritas adalah patuh yaitu sebanyak 26 orang $(45,61 \%)$.

3. Berdasarkan hasil penelitian menunjukkan bahwa ada hubungan antara fungsi manajemen kepala ruangan dengan kepatuhan perawat pelaksana dalam penerapan patient safety dengan nilai $p 0.000<0.05$. Hal ini menjelaskan bahwa terjadi penolakkan terhadap Ho atau Ha diterima sehingga disimpulkan ada hubungan yang signifikan antara kedua variabel, arah hubungan adalah positif yaitu jika fungsi manajemen kepala ruangan semakin baik maka kepatuhan perawat pelaksana dalam penerapan patient safety semakin baik.

\section{SARAN}

1. Bagi rumah sakit Umum Imelda Pekerja Indonesia Medan agar dapat membekali kepada perawat yang ada dirumah sakit dengan pengetahuan yang baru tentang patient safety dengan melakukan sosialisasi atau pelatihan terkait dengan patient safety agar dapat malukukan asuhan keperawatan dengan optimal kepada semua pasien.

2. Bagi perawat diharapkan meningkatkan motivasi dalam penlaksanaan patient safety agar lebih aktif untuk mencari informasi tentang patient safety dari media massa maupun dengan mengikuti seminar dan pelatihan patient safety.

\section{DAFTAR PUSTAKA}

Argote, L. (2011). "Organizational learning research: Past, present and future". Management Learning. 42 (4): 439 446. doi:10.1177/1350507611408217. ISSN $1350-5076$.

Arikunto, Suharsimi. (2007). Prosedur Penelitian Suatu Pendekatan Praktek. Jakarta: Penerbit Rineka Cipta.

Astuti, Y.,H.,N. (2010). Peran-Safety Leadership Dalam Membangun Budaya Keselamatan Yang Kuat, Seminar Nasional VI Sdm Teknologi Nuklir. Yogyakarta STTN BATAN \& Fakultas Saintek UIN SUKA.

Depkes RI. (2008). Panduan Nasional Keselamatan Pasien Rumah Sakit (Patient Safety) Utamakan Keselamatan Pasien. Jakarta: Depkes RI.

Gillies, D., A. (1996). Manajemen Keperawatan Suatu Pendekatan System. Edisi Ke Dua, Jakarta.

Kemenkes RI. (2017). Permenkes RI No. 11 2017 Tentang Keselamatan Pasien. Jakarta: Departemen Kesehatan RI.

Kementerian Kesehatan Republik Indonesia. (2011). Standar Akreditasi. Jakarta: Kemenkes RI.

Marquis, B., L., \& Huston, C., J. (2010). Kepemimpinan Dan Manajemen Keperawatan: Teori Dan Aplikasi. Edisi 4. Jakarta: EGC.

Notoatmodjo, S. (2010). Pendidikan Dan Perilaku Kesehatan. Jakarta: Rineka Cipta. 
Notoatmodjo, S. (2010). Promosi Kesehatan Dan Ilmu Perilaku. Jakarta: Rineka Cipta.

Nursalam. (2008). Konsep Dan Penerapan Metodologi Penelitian Ilmu Keperawatan. Jakarta: Salemba Medika.

Peraturan Menteri Kesehatan Republik Indonesia. (2012). Permenkes Nomor 012 Tahun 2012 tentang akreditasi Rumah Sakit. Jakarta: Depkes RI.

Persatuan Perawat Nasional Indonesia, PPNI. (2000). Kode Etik Keperawatan Lambang Panji PPNI Dan Ikrar Keperawatan. Jakarta: Pengurus Pusat PPNI.

Polit, D., F., \& Beck, C., T. (2012). Nursing: Generating And Assessing Evidence For Nursing Practice. $9^{\text {th }}$ ed. Philadelpia: Lippincott.
Potter, P., \& Anne., G. (2009). Buku Ajar Fundamental Keperawatan: Konsep, Proses Dan Praktik. Alih bahasa Yasmin A. Edisi 4. Volume 1. Jakarta: EGC.

Riduan. (2010). Skala Pengukuran Variabelvariabel Penelitian. Bandung: Alfabeta.

Setiadi. (2007). Konsep dan Penulisan Riset Keperawatan. Jakarta: Graha Ilmu.

Simamora H., R. (2012). Buku Ajar Menejemen Keperawatan. Jakarta: EGC.

Swansburg, R., C. (2000). Pengantar Kepemimpinan Dan Manajemen Keperawatan Untuk Perawat Klinis. Alih bahasa Suharyati Samba, editor Monica Ester. Jakarta: EGC.

Undang-Undang Republik Indonesia Nomor 38. (2014). Tentang Keperawatan. Jakarta: Departemen Kesehatan RI. 